\title{
Segregations for Onion Bulb Colors Reveal That Red Is Controlled by at Least Three Loci
}

\author{
Anil Khar \\ Department of Horticulture, University of Wisconsin, Madison, WI 53706 USA; and \\ National Research Centre for Onion and Garlic, Rajgurunagar, Pune Dist., Maharashtra, \\ India, 410505 \\ Jernej Jakse \\ Department of Horticulture, University of Wisconsin, Madison, WI 53706 USA; and Biotechnical \\ Faculty, University of Ljubljana, Jamnikarjeva 101, Ljubljana 1000, Slovenia \\ Michael J. Havey ${ }^{1}$ \\ USDA-ARS, Department of Horticulture, 1575 Linden Drive, University of Wisconsin, Madison, \\ WI 53706 USA
}

\begin{abstract}
Additional INDEX words. Allium cepa, complementary genes, seed color
Abstract. Onion (Allium cepa $\mathrm{L}$.) bulb color is controlled by at least five major loci $(I, C, G, L$, and $R$ ) and seedcoat color by one locus $(B)$. The authors developed families segregating for bulb and seedcoat colors, simple sequence repeats (SSRs), and single nucleotide polymorphisms (SNPs) in genomic amplicons of dihydroflavonol 4-reductase (DFR) and anthocyanidin synthase (ANS). The $B$ and $C$ loci were linked to SSRs on chromosomes 1 and 6 respectively. For all of three families, SNPs in DFR cosegregated with the $R$ locus conditioning red bulb color. In the family from $B 2246 \times B 11159$, red bulbs versus yellow bulbs were controlled by DFR and a locus $(L 2)$ linked at $6.3 \mathrm{cM}$ to ANS. The authors propose that yellow bulb onions have been independently selected numerous times and that yellow populations carry independent mutations in structural or regulatory genes controlling the production of red bulb color in onion.
\end{abstract}

Bulb color in onion is an economically important trait and is conditioned by the interaction of at least five major loci (Clarke et al., 1944; El-Shafie and Davis, 1967; Reiman, 1931). White bulbs result from a dominant allele at the $I$ locus or recessive alleles at the $C$ locus. Colored bulbs (chartreuse, light red, red, or yellow) require the homozygous recessive genotype at the $I$ locus and a dominant allele at the $C$ locus. In plants that are $i i C$-, a dominant allele at the $G$ locus produces golden yellow bulbs, and the homozygous recessive genotype $(i i C-g g)$ conditions chartreuse bulbs. Light-red bulbs are produced when the plant is $i i C$ - $G$ - and has dominant alleles at both the $L$ and $R$ loci; bulbs with deeper red colors are produced when both the $L$ and $R$ loci are homozygous dominant (El-Shafie and Davis, 1967). If either the $L$ or $R$ locus is homozygous recessive, yellow bulbs are produced. El-Shafie and Davis (1967) proposed that lightred bulb color produced when crossing two yellow onions [termed complementary light red by Jones and Peterson (1952)] results when the yellow parental plants have the genotypes iiCCGGLLrr and iiCCGGllRR.

Onion bulbs accumulate significant amounts of flavonoids, such as quercetin derivatives in yellow and anthocyanins in red

Received for publication 16 Apr. 2007. Accepted for publication 3 Aug. 2007. This work was supported by the Initiative for Future Agriculture and Food Systems grant 2001-52100-11344 from the USDA Cooperative State Research, Education, and Extension Service; a BOYSCAST (India) Fellowship to A.K.; and a Fulbright-Hayes Postdoctoral Fellowship to J.J.

Names are necessary to report factually on available data; however, the U.S. Department of Agriculture (USDA) neither guarantees nor warrants the standard of the product, and the use of the name by the USDA implies no approval of the product to the exclusion of others that may also be suitable.

${ }^{1}$ Corresponding author. E-mail: mjhavey@wisc.edu. bulbs (Fossen et al., 1996; Tsushida and Suzuki, 1995). Many of the structural genes in the flavonoid biosynthetic pathway have been cloned (Holton and Cornish, 1995). Kim et al. (2004a, 2005 c) correlated expression and segregation of dihydroflavonol 4-reductase (DFR) with yellow versus red bulb colors. In a confusing series of papers, variation at anthocyanidin synthase (ANS) was associated first with a new recessive locus $(p)$ conditioning pink bulbs (Kim et al., 2004b, 2005b), and then subsequently with four alleles at the $L$ locus [ANS- $p$ for recessive pink, $A N S-l$ and $A N S-L$ for the Brazilian and North American alleles of the complementary light-red system respectively (Kim et al., 2005a), and ANS-hl for dark red (Kim et al., 2006)]. No candidate genes have been identified for the $I, C$, or $G$ loci.

In this study we developed families segregating for dominant white $(I-)$, recessive white (cc), yellow (iiC-llR-, iiC-L-rr, and $i i C-l l r r)$, and light-red to red ( $i i C-L-R$-) bulb colors, as well as black $(B$-) versus brown $(b b)$ seeds (Davis, 1966). We scored segregations for simple sequence repeats (SSRs), bulb and seed colors, and single nucleotide polymorphisms (SNPs) in ANS and DFR to assess linkages among these important morphological and molecular markers. Our results support DFR as the $R$ locus and reveal a new locus $(L 2)$ linked at $6.3 \mathrm{cM}$ to ANS that conditions red bulb color in onion.

\section{Materials and Methods}

We obtained from N. Molenaar (formerly of Crookham Seed Co., Caldwell, ID) seed of a white onion (B11159) that produced flattened bulbs when grown in southern Wisconsin. Randomly selected bulbs from B11159 were individually 
self-pollinated to produce $\mathrm{S}_{1}$ families and testcrossed to MSU5718A $\times$ MSU8155B, a yellow bulb, male-sterile hybrid. Randomly selected B11159 plants were individually crossed as the male with plants from the inbred B2246, which has yellow bulbs (iiCCL-rr or iiCCllrr) and brown (bb) seeds. All selfpollinations and crosses were completed with mesh cages and house flies [Musca domestica L. (Rincon-Vitova Insectaries, Ventura, CA)] as described by Havey (1993). Hybrids were identified by white bulb color for progenies from B2246 as the maternal parent. Individual $\mathrm{F}_{2}$ plants were self-pollinated and testcrossed to the yellow bulb (iiCCL-rr or iiCCllrr), blackseed $(B B)$, male-sterile $(\mathrm{S}$ msms) hybrids MSU5718A $\times$ MSU8155B, B3350A $\times$ B2352B, or B1750A $\times$ B1794B. At least $50 \mathrm{~F}_{3}$ and testcross plants were scored for white or beige, red or light red, versus yellow bulb colors in field plots over at least 3 years. No effort was made to distinguish white from beige or red from light red. $\mathrm{F}_{3}$ seed was scored for black versus brown colors to assign genotypes at the $B$ locus to $\mathrm{F}_{2}$ plants. Goodness-of-fit to expect ratios for $\mathrm{F}_{2}$ and testcross families were completed using chi-square analyses on pooled data after confirming homogeneity of ratios (Gomez and Gomez, 1984).

A second family segregating for red versus yellow bulbs was developed from an inbred population (B8667) derived from a cross of U.S. Department of Agriculture Plant Introduction (PI) 262985 with the red inbred line B5361. Random bulbs from the $\mathrm{F}_{1} \mathrm{MSM}_{3}$ generation (where $\mathrm{M}$ is mass random pollinations among three to five bulbs) were self-pollinated and one family was segregated for yellow versus red bulbs. Random plants from this $\mathrm{F}_{1} \mathrm{MSM}_{3} \mathrm{~S}$ generation were again self-pollinated to produce the $\mathrm{F}_{1} \mathrm{MSM}_{3} \mathrm{~S}_{2}$ family and numbers of red bulbs versus yellow bulbs were scored over at least 3 years.

The third segregating family was BYG15-23 $\times$ AC43. We previously reported segregation of complementary light-red bulb color in testcrosses of $\mathrm{F}_{2}$ plants from this family with malesterile lines (King et al., 1998).

Polymorphisms in ANS and DFR have been associated with red versus yellow bulb colors in onion (Kim et al., 2004b, 2005b, c, 2006). Amplicons from ANS and DFR were generated using primers across promoter (Kim et al., 2004a, b, 2005b, 2005c, 2006) and coding regions (5'-CGTGATAATTGCAC CACCAG and 5'-ACAACTTCCGTTCCAGATGC for ANS and 5'-ATCAGCGGCTCTATTGCTGT and 5'-TCCCCA CATGCTCAATTAAA for DFR). Polymerase chain reactions (PCRs) had $50 \mathrm{ng}$ onion genomic DNA, $1 \mu \mathrm{M}$ each primer, $250 \mu \mathrm{M}$ deoxyribonucleotides (dNTPs), $5 \mathrm{U}$ Taq Polymerase (Promega, Madison, WI), $1.5 \mathrm{~mm} \mathrm{MgCl}_{2}, 50 \mathrm{~mm} \mathrm{KCl,} 10 \mathrm{~mm}$ Tris- $\mathrm{HCl}(\mathrm{pH}, 9.0)$, and $0.1 \%$ Triton X-100 (Sigma, St. Louis, $\mathrm{MO})$ in a total volume of $25 \mu \mathrm{L}$. Cycling conditions were $94{ }^{\circ} \mathrm{C}$ for $5 \mathrm{~min}$. followed by 39 cycles of $92^{\circ} \mathrm{C}$ for $1.15 \mathrm{~min}$., 58.7 (DFR) or 60.6 (ANS) ${ }^{\circ} \mathrm{C}$ for $2 \mathrm{~min}$., and $72{ }^{\circ} \mathrm{C}$ for $2 \mathrm{~min}$. Amplicons were gel purified and sequenced to confirm identity with ANS or DFR. DNA from parents and progenies of the three segregating families were scored for SNPs in the ANS and DFR coding regions.

Linkages were assessed among the major bulb and seed color loci, ANS, and DFR, and SSR markers. Procedures for DNA isolations from families, primer sequences, and production of genomic amplicons carrying SSRs were described by Martin et al. (2005) and Jakse et al. (2005). Simple sequence repeats segregating in the B2246-by-B11159 family were ACM006, ACM013, ACM045, ACM054 (5' -AAAGATGGTT TGTTGGTGGC and 5'-GAGTGAGAGGGGAAATGGAA), ACM066, ACM068 (5'-CGAAGGTGAAGGTGTACGGT and 5'-CAAATGGCTGCAATAAGCAA), ACM071, ACM093, ACM101, ACM102, АCM119, АCM124, $\mathrm{ACM} 132, \mathrm{ACM} 138, \mathrm{ACM} 146, \mathrm{ACM} 151, \mathrm{ACM} 152$, ACM154, ACM177, ACM218 (5'-CAACGGGCTATTTCGG TAGA and 5' -AATGCATGCTTTTGACCAC), ACM221, and ACM251. In the B8667 family, segregating SSRs were ACM006, ACM013, ACM045, ACM119, ACM132, ACM146, ACM151, ACM180, and ACM221. Many of these SSRs have been placed on the BYG15-23 × AC43 genetic map (Martin et al., 2005). MapManager (ver. 0.30, Center of Excellence in Bioinformatics and Life Sciences, Buffalo, NY) (Manly et al., 2001) was used at $P<0.001$ with the Kosambi

Table 1. Segregations of onion bulb colors in $\mathrm{S}_{1}, \mathrm{~F}_{2}$, and testcross families from B2246 by B11159.

\begin{tabular}{|c|c|c|c|c|c|c|c|c|c|c|}
\hline \multirow[b]{2}{*}{ Pedigree $^{z}$} & \multirow[b]{2}{*}{ Gen. ${ }^{\mathrm{y}}$} & \multirow[b]{2}{*}{ Fam. ${ }^{x}$} & \multicolumn{3}{|c|}{ Obs. $^{\mathrm{w}}$} & \multicolumn{3}{|c|}{ Exp. $^{\mathrm{w}}$} & \multirow[b]{2}{*}{ Assigned genotypes } & \multirow[b]{2}{*}{$P$ value } \\
\hline & & & $\mathrm{W}$ & $\mathrm{R}$ & $\mathrm{Y}$ & $\mathrm{W}$ & $\mathrm{R}$ & $\mathrm{Y}$ & & \\
\hline $\mathrm{A} \times \mathrm{B} 11159$ & $\mathrm{TC}$ & 4 & 348 & 0 & 0 & 1 & 0 & 0 & & \\
\hline B11159 @ & $\mathrm{S} 1$ & 4 & 182 & 0 & 0 & 1 & 0 & 0 & II & \\
\hline$(\mathrm{B} 2246 \times \mathrm{B} 11159) \otimes$ & $\mathrm{F} 2$ & 6 & 351 & 60 & 21 & 208 & 22 & 21 & $\operatorname{IiCcLlRr}$ & 0.005 \\
\hline $\mathrm{A} \times(\mathrm{B} 2246 \times \mathrm{B} 11159)$ & $\mathrm{TC}$ & 2 & 112 & 76 & 57 & 2 & 1 & 1 & & 0.093 \\
\hline$(\mathrm{B} 2246 \times \mathrm{B} 11159) \otimes$ & $\mathrm{F} 2$ & 2 & 111 & 12 & 15 & 208 & 27 & 21 & $\mathrm{IiCcLlRr}$ & 0.437 \\
\hline$(\mathrm{B} 2246 \times \mathrm{B} 11159) \otimes$ & $\mathrm{F} 2$ & 1 & 6 & 10 & 4 & 16 & 27 & 21 & $i i C c L l R r$ & 0.837 \\
\hline $\mathrm{A} \times(\mathrm{B} 2246 \times \mathrm{B} 11159)$ & $\mathrm{TC}$ & 2 & 122 & 0 & 81 & 1 & & 1 & & 0.004 \\
\hline$(\mathrm{B} 2246 \times \mathrm{B} 11159) \otimes$ & $\mathrm{F} 2$ & 2 & 132 & 0 & 23 & 13 & & 3 & IiCcLlrr & 0.212 \\
\hline $\mathrm{A} \times(\mathrm{B} 2246 \times \mathrm{B} 11159)$ & $\mathrm{TC}$ & 1 & 47 & 16 & 23 & 2 & 1 & 1 & & 0.390 \\
\hline$(\mathrm{B} 2246 \times \mathrm{B} 11159) \otimes$ & $\mathrm{F} 2$ & 1 & 55 & 22 & 3 & 28 & 12 & 2 & $I i C c L L R r$ & 0.106 \\
\hline
\end{tabular}

${ }^{\mathrm{z}} \mathrm{A}$, yellow bulb, male-sterile plant with expected genotype iiCCLLrr.

${ }^{\mathrm{y}}$ Gen., generation; TC, testcross.

${ }^{\mathrm{x}}$ Numbers of families (Fam.).

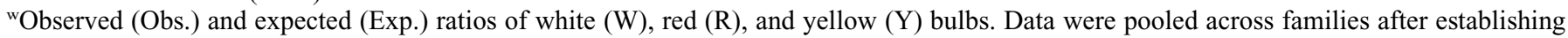
homogeneity of ratios.

verobability $(P)$ of goodness-of-fit from chi-square analyses. 
mapping function to assess linkages among SNPs in ANS and DFR, SSRs, and the bulb and seed color loci.

Copy numbers of ANS and DFR in the onion genome were estimated by hybridization of PCR amplicons to DNAs isolated from leaf tissue combined from at least $25 \mathrm{~F}_{3}$ progenies from the B2246 × B11159 family. Digestion of DNAs with EcoRI, EcoRV, or HindIII, gel electrophoresis, labeling and hybridization conditions, and autoradiography were described by King et al. (1998).

\section{Results and Discussion}

SEgRegations FOR BULB AND SEED COLOR LOCI IN THE B2246 $\times$ B11159 FAMILY. All seed from self-pollination of random bulbs from B11159 was black $(B B)$ and produced only white bulbs (Table 1). In crosses of B11159 plants to yellow bulb, malesterile lines, only white bulbs were produced (Table 1), revealing that B11159 was homozygous dominant at the $I$ locus. The testcross and $\mathrm{F}_{2}$ progenies from hybrids between B2246 by B11159 segregated for white, red, and yellow bulbs (Table 1). No chartreuse bulbs were produced.

One family (17400) from B2246 × B11159 was chosen for further study because it segregated for bulb and seed colors. Individual $\mathrm{F}_{2}$ plants were self-pollinated to produce $\mathrm{F}_{3}$ families and crossed to male-sterile plants to produce the testcross generations. Because these male-sterile lines produce only yellow bulbs in crosses with North American longday, yellow bulb inbreds, they should be homozygous recessive at the $R$ locus; however, they could carry dominant alleles at the $L$ locus (El-Shafie and Davis, 1967; Jones and Peterson, 1952). Testcross segregations for bulb colors fit expected ratios for 46 of 51 families, assuming that the yellow bulb, male-sterile lines were iiCCLLrr or less commonly iiCCLlrr (Table 2). $\mathrm{F}_{3}$ segregations fit expected ratios for 45 of $55 \mathrm{~F}_{3}$ families, excluding 30 families with all-white bulbs (II or $c c$ ). Segregations revealed that B2246 must have contributed

Table 2. Segregations of onion bulb colors in $\mathrm{F}_{3}$ and testcross families from B2246 $\times$ B11159.

\begin{tabular}{|c|c|c|c|c|c|c|c|c|c|c|}
\hline \multirow[b]{2}{*}{ Pedigree $^{z}$} & \multirow[b]{2}{*}{ Gen. ${ }^{\mathrm{y}}$} & \multirow[b]{2}{*}{ Assigned genotype } & \multirow[b]{2}{*}{ Fam. ${ }^{x}$} & \multicolumn{3}{|c|}{ Obs. $^{\mathrm{w}}$} & \multicolumn{3}{|c|}{ Exp. $^{\mathrm{w}}$} & \multirow[b]{2}{*}{$P$ value $^{\mathrm{v}}$} \\
\hline & & & & $\mathrm{W}$ & $\mathrm{R}$ & $\mathrm{Y}$ & $\mathrm{W}$ & $\mathrm{R}$ & $\mathrm{Y}$ & \\
\hline$\overline{\mathrm{A} \times[(\mathrm{B} 2246 \times \mathrm{B} 11159) \otimes]}$ & $\mathrm{TC}$ & & 27 & 1721 & 0 & 0 & 1 & 0 & 0 & \\
\hline$[(\mathrm{B} 2246 \times \mathrm{B} 11159) \otimes] \otimes$ & F3 & $I I-$ & 27 & 883 & 0 & 0 & 1 & 0 & 0 & \\
\hline$[(\mathrm{B} 2246 \times \mathrm{B} 11159) \otimes] \otimes$ & $\mathrm{F} 3$ & IiCCLLRR & 3 & 102 & 20 & 0 & 3 & 1 & 0 & 0.090 \\
\hline $\mathrm{A} \times[(\mathrm{B} 2246 \times \mathrm{B} 11159) \otimes]$ & TC & & 2 & 60 & 36 & 33 & 2 & 1 & 1 & 0.681 \\
\hline$[(\mathrm{B} 2246 \times \mathrm{B} 11159) \otimes] \otimes$ & F3 & IiCCLLRr & 3 & 111 & 34 & 18 & 12 & 3 & 1 & 0.025 \\
\hline$[(\mathrm{B} 2246 \times \mathrm{B} 11159) \otimes] \otimes$ & F3 & IiCCLlRr & 12 & 494 & 101 & 68 & 48 & 9 & 7 & 0.622 \\
\hline $\mathrm{A} \times[(\mathrm{B} 2246 \times \mathrm{B} 11159) \otimes]$ & $\mathrm{TC}$ & & 1 & 30 & 15 & 14 & 2 & 1 & 1 & 0.975 \\
\hline$[(\mathrm{B} 2246 \times \mathrm{B} 11159) \otimes] \otimes$ & $\mathrm{F} 3$ & IiCCllRr & 1 & 21 & 9 & 4 & 48 & 9 & 7 & 0.103 \\
\hline $\mathrm{A} \times[(\mathrm{B} 2246 \times \mathrm{B} 11159) \otimes]$ & $\mathrm{TC}$ & & 2 & 58 & 36 & 0 & 1 & 1 & 0 & 0.769 \\
\hline$[(\mathrm{B} 2246 \times \mathrm{B} 11159) \otimes] \otimes$ & $\mathrm{F} 3$ & $\operatorname{IiCcLLRR}$ & 4 & 180 & 28 & 1 & 13 & 3 & 0 & 0.149 \\
\hline$[(\mathrm{B} 2246 \times \mathrm{B} 11159) \otimes] \otimes$ & $\mathrm{F} 3$ & $I i C c L L R r$ & 2 & 150 & 18 & 9 & 52 & 9 & 3 & 0.327 \\
\hline $\mathrm{A} \times[(\mathrm{B} 2246 \times \mathrm{B} 11159) \otimes]$ & $\mathrm{TC}$ & & 3 & 115 & 62 & 49 & 2 & 1 & 1 & 0.457 \\
\hline$[(\mathrm{B} 2246 \times \mathrm{B} 11159) \otimes] \otimes$ & $\mathrm{F} 3$ & IiCcLlRr & 6 & 359 & 28 & 12 & 208 & 27 & 21 & 0.000 \\
\hline $\mathrm{A} \times[(\mathrm{B} 2246 \times \mathrm{B} 11159) \otimes]$ & $\mathrm{TC}$ & & 3 & 103 & 13 & 83 & 2 & 1 & 1 & 0.000 \\
\hline$[(\mathrm{B} 2246 \times \mathrm{B} 11159) \otimes] \otimes$ & $\mathrm{F} 3$ & IiCcllRr & 3 & 125 & 0 & 35 & 52 & 0 & 12 & 0.557 \\
\hline $\mathrm{A} \times[(\mathrm{B} 2246 \times \mathrm{B} 11159) \otimes]$ & $\mathrm{TC}$ & & 9 & 288 & 0 & 272 & 1 & 0 & 1 & 0.796 \\
\hline$[(\mathrm{B} 2246 \times \mathrm{B} 11159) \otimes] \otimes$ & F3 & IiCcllrr & 9 & 277 & 0 & 72 & 13 & 0 & 3 & 0.667 \\
\hline $\mathrm{A} \times[(\mathrm{B} 2246 \times \mathrm{B} 11159) \otimes]$ & $\mathrm{TC}$ & & 1 & 33 & 18 & 16 & 2 & 1 & 1 & 0.935 \\
\hline$[(\mathrm{B} 2246 \times \mathrm{B} 11159) \otimes] \otimes$ & $\mathrm{F} 3$ & IiccLLRr & 1 & 44 & 0 & 0 & 1 & 0 & 0 & \\
\hline $\mathrm{A} \times[(\mathrm{B} 2246 \times \mathrm{B} 11159) \otimes]$ & $\mathrm{TC}$ & & 1 & 17 & 6 & 5 & 2 & 1 & 1 & 0.507 \\
\hline$[(\mathrm{B} 2246 \times \mathrm{B} 11159) \otimes] \otimes$ & F3 & $\operatorname{IiccLlRR}$ & 1 & 51 & 0 & 0 & 1 & 0 & 0 & \\
\hline $\mathrm{A} \times[(\mathrm{B} 2246 \times \mathrm{B} 11159) \otimes]$ & $\mathrm{TC}$ & & 1 & 40 & 21 & 25 & 2 & 1 & 1 & 0.673 \\
\hline
\end{tabular}

${ }^{\mathrm{z}} \mathrm{A}$, yellow bulb, male-sterile plant with expected genotype iiCCLLrr or iiCCLlrr.

${ }^{\mathrm{y}} \mathrm{Gen}$., generation; $\mathrm{TC}$, family from testcross of $\mathrm{F}_{2}$ plants to male-sterile (A) line.

${ }^{\mathrm{x}}$ Numbers of families (Fam.).

${ }^{\mathrm{w}}$ Observed (Obs.) and expected (Exp.) ratios of white (W), red (R), and yellow (Y) bulbs. Data were pooled across families after establishing homogeneity of ratios.

vProbability $(P)$ of goodness-of-fit from chi-square analyses. 
recessive alleles and B11159 dominant alleles at the $L$ and $R$ loci.

Amplicons were produced from the promoter regions of ANS and DFR; however, we never observed any of the polymorphisms reported by Kim et al. (2004a, b, 2005a, b, c, 2006). Amplicons produced from the coding regions of ANS and DFR were essentially identical to Genbank accessions AY585678 and AY221252 respectively, and SNPs were revealed that segregated in the B2246 $\times$ B11159 family. For ANS, one T/C SNP was identified at position 358 (Genbank accessions BV722873 and BV722872 for B2246 and B11159 respectively). One C/T SNP in DFR segregated at position 257 (Genbank accessions BV722871 and BV722870). Linkage analyses revealed that ANS and DFR were independently inherited, as expected, because Masuzaki et al. (2006) assigned these genes to chromosomes 4 and 7 respectively of onion. Red bulbs versus yellow bulbs in the B2246 $\times$ B11159 family cosegregated with DFR and a locus linked at $6.3 \mathrm{cM}$ to ANS. Bulb color segregations and SNP genotypes for recombinant families are shown in Table 3. Our results demonstrate that light-red to red bulb color in the B2246 $\times$ B11159 family is conditioned by dominant alleles at two loci, consistent with the model proposed by El-Shafie and Davis (1967). One of these loci is identical or tightly linked to DFR. The second locus did not cosegregate with ANS, but showed linkage to ANS at $6.3 \mathrm{cM}$ and was named $L 2$.

SEgREgations FOR RED BULBS VERSUS Yellow BULBS FROM B8667B. Segregations for red bulbs versus yellow bulbs in the B8667 family fit the expected 1:2:1 ratio (13:39:20, $P=0.394)$. Amplicons produced for ANS were monomorphic in this family. Amplicons from DFR were more than $98 \%$ similar to Genbank accession AY221252, and an A/T SNP in DFR was identified at position 296 (Genbank accessions BV722868 and BV722869 for red and yellow alleles respectively). Linkage analyses demonstrated that red bulbs versus yellow bulbs cosegregated with SNPs in DFR.

SEGREgATIONS FOR RED BULBS VERSUS YELLOW BULBS IN TESTCROSSES OF BYG15-23 $\times$ AC43 PROGENIES. We previously reported that yellow $\mathrm{F}_{2}$ bulbs from the BYG15-23 $\times \mathrm{AC} 43$ segregating family occasionally produced red progenies in testcrosses with yellow male-sterile lines (King et al., 1998). An A/T SNP was identified at position 120 of genomic amplicons of DFR (Genbank accessions BV722867 and BV722866 and AC43 and BYG15-23 respectively); no SNPs were revealed in ANS amplicons. Single nucleotide polymorphisms in DFR cosegregated with complementary light-red bulbs in testcrosses of 115 plants from BYG15-23 $\times$ AC43. We originally named a locus ( $C r b-1$ for complementary red bulb-1) for this trait (King et al., 1998); however, this name is not appropriate because a dominant allele at DFR conditioned complementary light-red bulbs in this family. Dihydroflavonol 4-reductase mapped to chromosome 7 of onion at $11.1 \mathrm{cM}$ from AOB212 (Martin et al., 2005), in agreement with Masuzaki et al. (2006), who used alien addition lines to assign DFR to chromosome 7.

LINKAGE ANALYSES FOR BULB AND SEEDCOAT COLORS IN ONION. We previously described mapping of SSR markers in onion (Martin et al., 2005), of which 22 segregated in the B2246 $\times$ B11159 family and nine in the B8667B family. Linkage analyses among the bulb color loci and SSRs revealed that $I$ was linked at $21.0 \mathrm{cM}$ to ACM006 (currently unmapped in onion), $B$ was assigned to chromosome 1 , and $C$ to chromosome 6 (Fig. 1). Single nucleotide polymorphisms in ANS and DFR were not linked to any of the SSRs.

GENETIC MODEL FOR RED BULB COLOR IN ONION. Crosses among populations of yellow bulb onions occasionally produce light-red progenies, for example between North American long-day storage inbreds or short-day Grano types with European Rijnsburger or Brazilian populations (Jones and Peterson, 1952). These light-red hybrids complicate the production of yellow hybrids from crosses among divergent inbred lines. El-Shafie and Davis (1967) proposed that complementary light-red bulbs are conditioned by dominant alleles at the $R$ and $L$ loci, with deeper red colors occurring when $R$ or $L$ loci are homozygous dominant. The $L$ locus was proposed to be ANS (Kim et al., 2005c) and the $R$ locus may be DFR (Kim et al., 2004b). Hybridizations revealed that ANS is single copy, and

Table 3. Parental genotypes and examples of segregations for onion bulb colors and single nucleotide polymorphisms at anthocyanidin synthase (ANS) and dihydroflavonol 4-reductase (DFR) for $\mathrm{F}_{3}$ and testcross families from B2246 by B11159.

\begin{tabular}{|c|c|c|c|c|c|c|c|c|c|c|c|}
\hline \multirow[b]{2}{*}{ Family $^{z}$} & \multirow[b]{2}{*}{ Gen..$^{y}$} & \multicolumn{2}{|c|}{$\mathrm{SNP}^{\mathrm{x}}$} & \multirow[b]{2}{*}{ Genotype $^{\mathrm{w}}$} & \multicolumn{3}{|c|}{ Obs. ${ }^{\mathrm{v}}$} & \multicolumn{3}{|c|}{ Exp. $^{\mathrm{v}}$} & \multirow[b]{2}{*}{$P$ value ${ }^{\mathrm{u}}$} \\
\hline & & $\overline{\mathrm{ANS}}$ & $\overline{\mathrm{DFR}}$ & & $\mathrm{W}$ & $\mathrm{R}$ & $\mathrm{Y}$ & W & $\mathrm{R}$ & $\mathrm{Y}$ & \\
\hline B11159 & P1 & $\mathrm{T}$ & $\mathrm{C}$ & IIccLLRR & All & 0 & 0 & 1 & 0 & 0 & \\
\hline B2246 & $\mathrm{P} 2$ & $\mathrm{C}$ & $\mathrm{T}$ & $i i C C l l r r$ & 0 & 0 & All & 0 & 0 & 1 & \\
\hline 19100 & F3 & $\mathrm{C}$ & $\mathrm{H}$ & IiCCLIRr & 28 & 7 & 8 & 48 & 9 & 7 & 0.221 \\
\hline $\mathrm{A} \times 19124$ & $\mathrm{TC}$ & & & & 35 & 23 & 26 & 2 & 1 & 1 & 0.280 \\
\hline 19124 & $\mathrm{~F} 3$ & $\mathrm{C}$ & $\mathrm{H}$ & IiCCLlRr & 36 & 8 & 5 & 48 & 9 & 7 & 0.897 \\
\hline 19136 & F3 & $\mathrm{C}$ & $\mathrm{H}$ & IiCCLlRr & 21 & 9 & 4 & 48 & 9 & 7 & 0.103 \\
\hline $\mathrm{A} \times 19142$ & $\mathrm{TC}$ & & & & 33 & 13 & 17 & 2 & 1 & 1 & 0.722 \\
\hline 19142 & F3 & $\mathrm{C}$ & $\mathrm{H}$ & IiCcLlRr & 49 & 4 & 1 & 208 & 27 & 21 & 0.153 \\
\hline
\end{tabular}

${ }^{\mathrm{z}} \mathrm{A}$, yellow bulb, male-sterile plant with expected genotype iiCCLLrr.

${ }^{\text {y }}$ Gen., generation; P, parent; TC, testcross family to male-sterile (A) plant.

${ }^{\mathrm{x}} \mathrm{SNP}$, single nucleotide polymorphism.

${ }^{\mathrm{w}}$ Genotype assigned based on observed segregations.

${ }^{\mathrm{v}}$ Observed (Obs.) and expected (Exp.) ratios of white (W), red (R), and yellow (Y) bulbs.

${ }^{u} P=$ probability of goodness-of-fit from chi-square analyses.

Dihydroflavonol 4-reductase (DFR) cosegregated with one of the two loci conditioning red bulb color. If anthocyanidin synthase (ANS) were the second locus, $\mathrm{F}_{2}$ plants homozygous for the $\mathrm{C}$ allele at ANS should not produce red bulbs in the $\mathrm{F}_{3}$ and testcross families. 


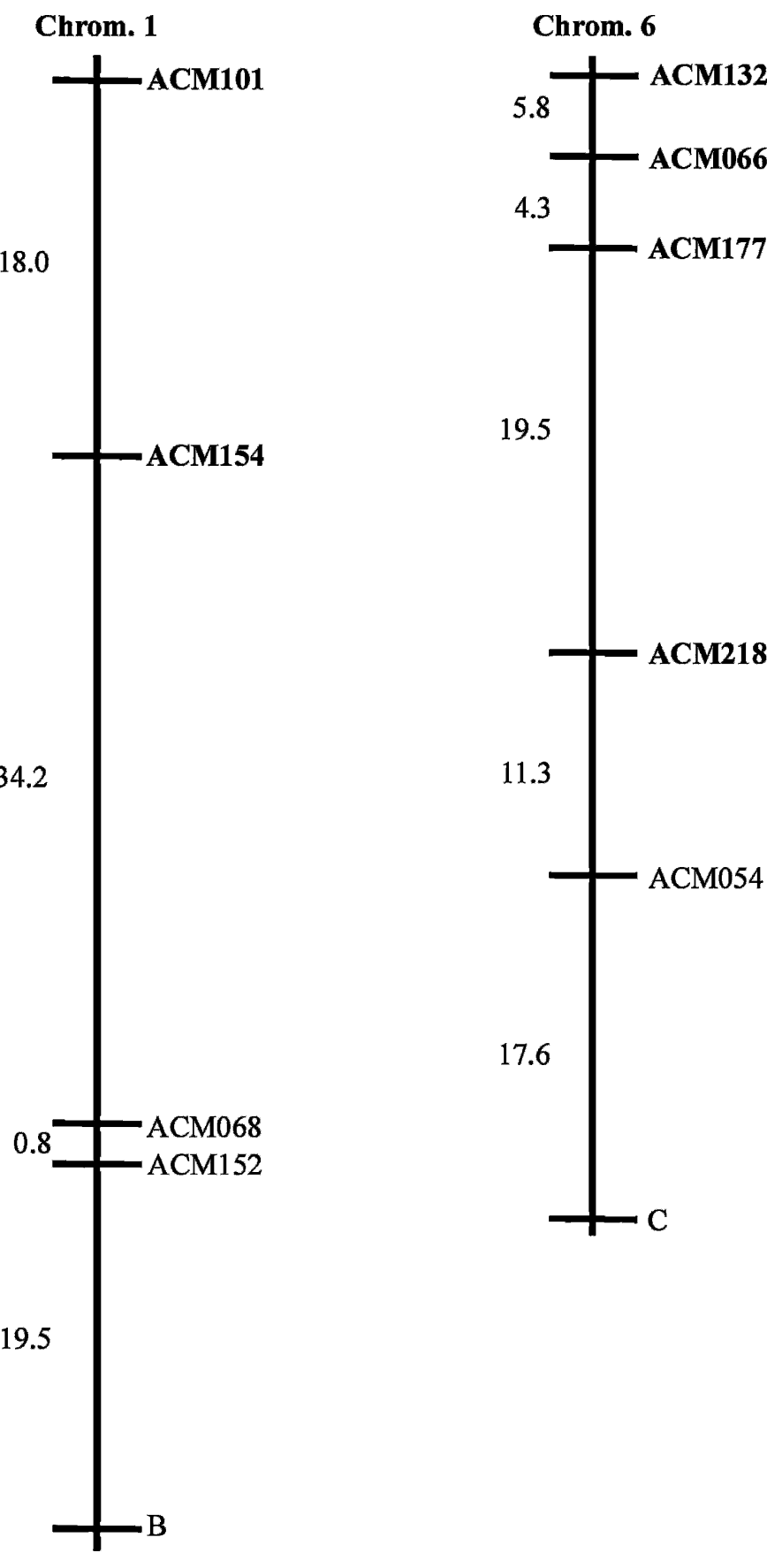

Fig. 1. Linkages among simple sequence repeats (ACM) and the $B$ and $C$ loci in onion. Markers shown in bold text were previously mapped by Martin et al. (2005).

numerous copies of DFR exist in the onion genome (Fig. 2). Our analyses support DFR as the $R$ locus of onion; however, duplicated copies of DFR may also control the appearance of red bulbs. In the B2246 $\times$ B11159 family, red bulb color did not cosegregate with single-copy ANS, but with a second locus (L2) linked at $6.3 \mathrm{cM}$ to ANS on chromosome 4 . We propose that yellow bulb onions have been independently selected numerous times from white or red populations and that yellow onions carry independent mutations in structural or regulatory genes controlling the production of anthocyanins. Two of these genes are DFR and ANS, and correspond to the $R$ and $L$ loci

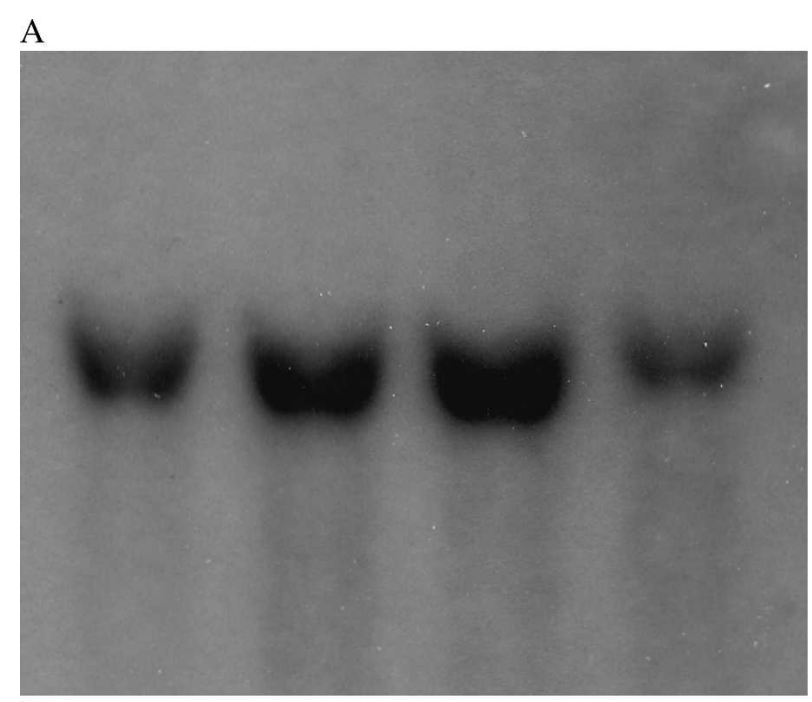

B

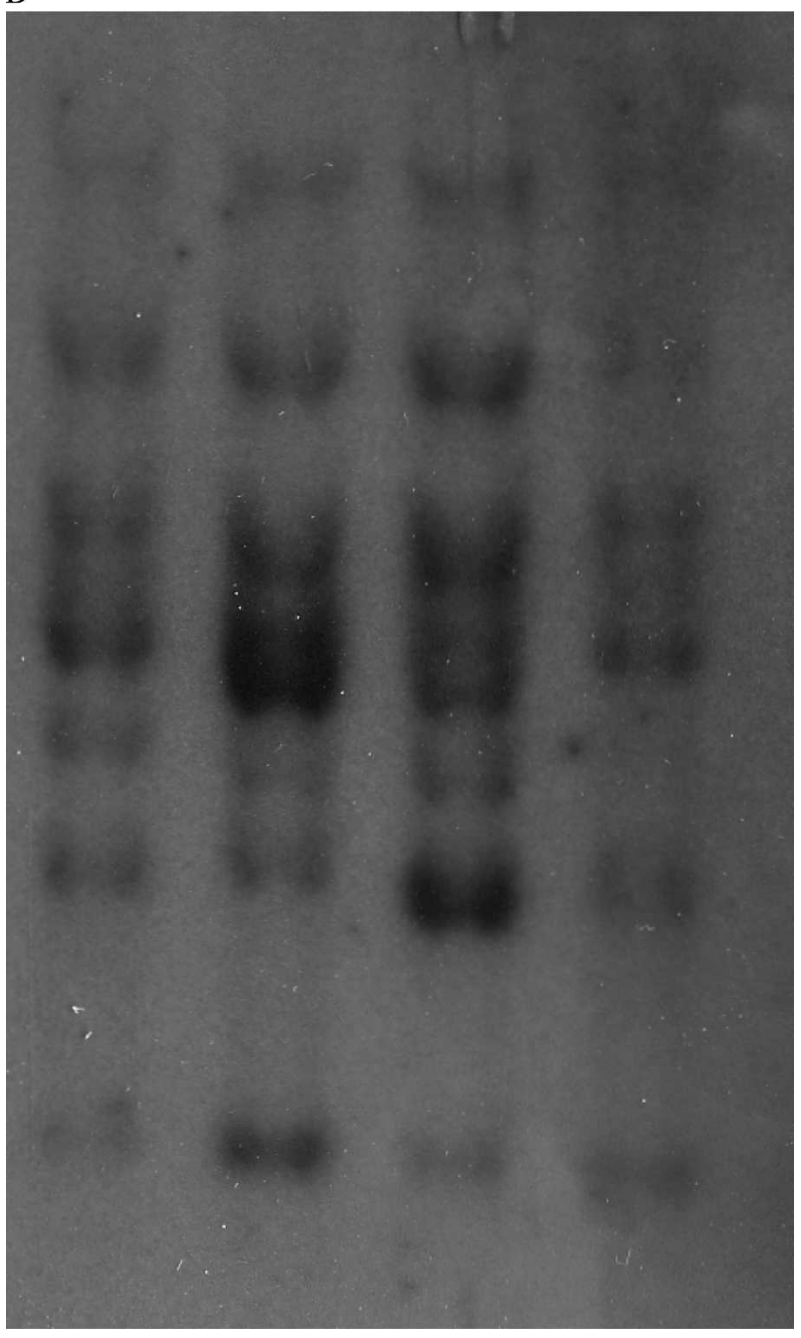

Fig. 2. (A, B) Autoradiograms from hybridizations of anthocyanidin synthase (A) and dihydroflavonol 4-reductase (B) to gel blots of EcoRV-digested DNA from four segregating progenies from the B2246 $\times$ B11159 family of onion.

(Kim et al., 2004a, 2005c) respectively. Our results demonstrate that dominant alleles at both DFR and L2, an additional locus linked at $6.3 \mathrm{cM}$ to ANS on chromosome 4 , also condition red bulb color in onion. 


\section{Literature Cited}

Clarke, A.E., H.A. Jones, and T.M. Little. 1944. Inheritance of bulb color in the onion. Genetics 29:569-575.

Davis, E. 1966. An improved method of producing hybrid onion seed. J. Hered. 57:55-57.

El-Shafie, M.W. and G.N. Davis. 1967. Inheritance of bulb color in the onion (Allium cepa L.). Hilgardia 9:607-622.

Fossen, T., O.M. Andersen, D.O. Ovstedal, A.T. Pedersen, and A. Raknes. 1996. Characteristic anthocyanin pattern from onions and other Allium spp. J. Food Sci. 61:703-706.

Gomez, K.A. and A.A. Gomez. 1984. Statistical procedures for agricultural research. Wiley, New York.

Havey, M.J. 1993. Estimation of outcrossing using house flies for fertile-by-fertile crosses in onion. Allium Improvement Nwsl. 3:1214.

Holton, T.A. and E.C. Cornish. 1995. Genetics and biochemistry of anthocyanin biosynthesis. Plant Cell 7:1071-1083.

Jakse, J., W. Martin, J. McCallum, and M.J. Havey. 2005. Single nucleotide polymorphisms, indels, and simple sequence repeats for onion cultivar identification. J. Amer. Soc. Hort. Sci. 130:912-917. Jones, H.A. and C.E. Peterson. 1952. Complementary factors for lightred bulb color in onions. Proc. Amer. Soc. Hort. Sci. 59:457.

Kim, S., H. Bang, K.S. Yoo, and L.M. Pike. 2006. Identification of the fourth allele of ANS (anthocyanidin synthase) gene and its effect on red color intensity in onions (Allium cepa). Euphytica 149:45-51.

Kim, S., M.L. Binzel, S. Park, K.S. Yoo, and L.M. Pike. 2004a. Inactivation of DFR (dihydroflavonol 4-reductase) gene transcription results in blockage of anthocyanin production in yellow onions (Allium cepa). Mol. Breed. 14:253-263.

Kim, S., M.L. Binzel, K.S. Yoo, S. Park, and L.M. Pike. 2004b. Pink (P), a new locus responsible for a pink trait in onions (Allium cepa) resulting from natural mutations of anthocyanidin synthase. Mol. Genet. Genomics 272:18-27.
Kim, S., R. Jones, K.S. Yoo, and L.M. Pike. 2005a. The $L$ locus, one of complementary genes required for anthocyanin production in onions (Allium cepa), encodes anthocyanidin synthase. Theor. Appl. Genet. 111:120-127.

Kim, S., K.S. Yoo, and L.M. Pike. 2005b. Development of a codominant PCR-based marker for allelic selection of the pink trait in onions (Allium cepa), based on the insertion mutation in the promoter of the anthocyanidin synthase gene. Theor. Appl. Genet. 110:628633.

Kim, S., K.S. Yoo, and L.M. Pike. 2005c. Development of a PCRbased marker utilizing a deletion mutation in the dihydroflavonol 4-reductase (DFR) gene responsible for the lack of anthocyanin production in yellow onions (Allium cepa). Theor. Appl. Genet. 110:588-595.

King, J.J., J.M. Bradeen, O. Bark, J.A. McCallum, and M.J. Havey. 1998. A low-density genetic map of onion reveals a role for tandem duplication in the evolution of an extremely large diploid genome. Theor. Appl. Genet. 96:52-62.

Manly, K.F., R.H. Cudmore, Jr., and J.M. Meer. 2001. Map Manager QTX, cross-platform software for genetic mapping. Mamm. Genome 12:930-932.

Martin, W., J. McCallum, M. Shigyo, J. Jakse, J.C. Kuhl, N. Yamane, K.C. Sink, C.D. Town, and M.J. Havey. 2005. Genetic mapping of expressed sequences in onion and in silico comparisons show scant colinearity with rice. Mol. Genet. Genomics 274:197-204.

Masuzaki, S., M. Shigyo, and N. Yamauchi. 2006. Complete assignment of structural genes involved in flavonoid biosynthesis influencing bulb color to individual chromosomes of shallot (Allium cepa L.). Genes Genet. Syst. 81:255-263.

Reiman, G.H. 1931. Genetic factors for pigmentation in the onion and their relationship to disease resistance. J. Agr. Res. 42:251-278.

Tsushida, T. and M. Suzuki. 1995. Isolation of flavonoid-glycosides in onion and identification by chemical synthesis of the glycosides. J. Jpn. Soc. Food Sci. Technol. 42:100-108. 